\title{
PENGARUH JENIS FLUIDA TERHADAP UNJUK KERJA MINIATUR PEMBANGKIT LISTRIK TENAGA UAP
}

\author{
Nurul Wahidah ${ }^{1}$, Ihsan $^{1}$, Sri Zelviani $^{1}$, Narti $^{1}$, dan Firdaus Alam Abadi ${ }^{1}$ \\ ${ }^{1}$ Jurusan Fisika, Fakultas Sains dan Teknologi, Universitas Islam Negeri Alauddin Makassar \\ email: nurul.wahidah@uin-alauddin.ac.id, ihsanphysics@uin-alauddin.ac.id, sri.zelviani@uin- \\ alauddin.ac.id, narti@uin-alauddin.ac.id, firdaus.a.a@uin-alauddin.ac.id
}

\begin{abstract}
The research has conducted the types of bio briquette fuels on the performance of miniature Steam Powered Electric Plants (PLTU). The main component of miniature consist of the furnace, boiler, and turbine, with the dimensions around is $15 \mathrm{~cm} \times 15 \mathrm{~cm} \times 50 \mathrm{~cm}$. The type of liquid used as a miniature is aquades which has a turbidity level is 0 NTU, well water is $1.2 \mathrm{NTU}$ and river water is 6,5 NTU. The conclution of this researched is the type of fluid influences the performance of miniature. The highest electric power is generated by miniature with a type of aquades fluid that is equal to 0.021 watt. While the well water and river water samples obtained electrical power respectively 0.006 watts and 0.004 watt.
\end{abstract}

Keywords: aquades, well water, river water, electrical power, miniatur PLTU

\section{PENDAHULUAN}

Pada era teknologi sekarang ini, kebutuhan manusia terhadap listrik semakin meningkat. Dengan meningkatnya kebutuhan tersebut, maka inovasi pembangkit listrik sangat dibutuhkan. Salah satu pembangkit listrik yang berkembang saat ini adalah Pembangkit Listrik Tenaga Uap (PLTU).

Dalam PLTU, energi primer yang dikonversikan menjadi energi listrik adalah bahan bakar. Bahan bakar yang digunakan dapat berupa batu bara (padat), minyak (cair), atau gas. Adakalanya PLTU menggunakan kombinasi beberapa macam bahan bakar. Konversi energi tingkat pertama yang berlangsung dalam PLTU adalah konversi energi primer menjadi energi panas (kalor). Hal ini dilakukan dalam ruang bakar dari ketel uap PLTU. Energi panas ini kemudian dipindahkan ke dalam air yang ada dalam pipa ketel untuk menghasilkan uap yang dikumpulkan dalam drum dari ketel. Uap dari drum ketel dialirkan ke turbin uap. Dalam turbin uap, energi (entalpy) uap di konversikan menjadi energi mekanis penggerak generator, dan akhirnya energi mekanik dari turbin uap ini dikonversikan menjadi energi listrik oleh generator. (Marsudi, 2011)

Kinerja dari PLTU antara lain ditentukan oleh kualitas bahan bakar dan air dalam ketel uap. Jenis air yang digunakan akan mempengaruhi kualitas uap air yang dihasilkan. Uap air ini memiliki peranan yang penting dalam memutar turbin, sehingga secara tidak langsung jenis air akan menentukan kinerja dari PLTU.

Jenis air dapat dibedakan berdasarkan beberapa parameter, antara lain: kandungan oksigen terlarut, tingkat kekeruhan, derajat keasaman, dan lain-lain. Pada umumnya air lingkungan yang telah tercemar, kandungan oksigennya sangat rendah. Hal ini karena oksigen yang terlarut dalam air dalam air di serap oleh mikroorganisme untuk memecah atau mendegradasi bahan buagan organik sehingga menjadi bahan yang lebih mudah menguap. Selain dari itu bahan 
buangan organik juga dapat bereaksi dengan oksigen yang terlarut didalam air sehingga makin sedikit sisa kandungan oksigen dalam air. (Agnes, 2005)

Sumber daya air tersebut harus dilindungi agar tetap dimanfaatkan dengan baik oleh manusia dan mahluk hidup lainya pemanfaatan air untuk berbagai kepentingan harus dilakukan secara bijaksana dengan memperhitungkan kepentingan generasi sekarang dan generasi yang akan datang, beberapa sumber air yang banyak dimanfaatkan untuk memenuhi kebutuhan hidup manusia dan makhluk hidup lainnya yaitu sungai, sumur, dan aquades. Air ini sangat berguna bagi lingkungan baik untuk berbagai kegiatan, seperti pen elitian, pertanian, industri dan domestik. Parameter oksigen terlarut dapat digunakan sebagai indikator tingkat keragaman air. Oksigen memegang peran penting sebagai indikator kualitas perairan, karena oksigen terlarut berperan dalam proses oksidasi dan reduksi bahan organik dan anorganik. Karena proses oksidasi reduksi maka inilah peran oksigen terlarut sangat penting untuk membantu mengurangi bahan pencemaran pada perairan secara alami. (Azwar, 2013)

Suatu hal yang penting dalam masalah pencemeran suatu perairan adalah bahwa tingkat keseriusan masalah pencemaran tidak hanya tergantung pada tingkat toksisitas polutan yan tinggi. Limbah domestik terdiri dari karakteristik fisika salah satunya adalah parameter tingkat kekeruhan. Karakteristik kimia antara lain BOD, COD, dan PH. (Sri Kandi, 1992)

Penelitian pengembangan media praktikum juga sering dilakukan dalam upaya mencari solusi alternatif permasalahan dalam pembelajaran. Penggunaan media praktikum dalam proses belajar mengajar dapat membangkitkan keinginan dan minat yang baru, membangkitkan motivasi dan rangsangan kegiatan pembelajaran dan bahkan membawa pengaruh-pengaruh psikologis terhadap mahasiswa. Penggunaan media praktikum akan sangat membantu efektifitas proses pembelajaran serta penyampaian pesan dan isi pelajaran sehingga dapat membantu mahasiswa meningkatkan pemahaman karena menyajikan informasi secara menarik dan terpercaya.

Penelitian terdahulu menyebutkan bahwa sampah bisa dimanfaatkan untuk berbagai hal, diantaranya untuk ekonomi, lingkungan dan energi. Salah satu pemanfaatan sampah adalah dengan memanfaatkannya untuk Pembangkit Listrik (Hermansyah, 2017). Pembangkit listrik ini bisa dengan pembakaran gas yang dihasilkan oleh sampah organik. Sampah organic dapat dibuat menjadi briket. Bio briket yang dihasilkan mempunyai nilai kalor yang tinggi bahkan lebih besar dari nilai kalor briket batubara, sehingga penelitian tentang biobriket untuk mengatasi keterbatasan batubara masih sangat diperlukan.

Berdasarkan paparan di atas, maka penulis bermaksud mengeksplorasi sampah atau limbah menjadi briket dan diaplikasikan melalui suatu alat atau mesin yang akan dibuat untuk ramah lingkungan. Pada penelitian ini, penulis ingin mengetahui pengaruh jenis fluida terhadap unjuk kerja miniatur pembangkit listrik tenaga uap air dengan sistem turbin uap sederhana. Jenis fluida yang digunakan adalah aquades, air sumur, dan air sungai.

\section{METODE PENELITIAN}

\section{Prosedur Kerja Titrasi COD}

Memasukan sampel air sebanyak $100 \mathrm{ml}$ ke dalam erlenmeyer, Menamabahkan asam sulfat $\left(\mathrm{H}_{2} \mathrm{SO}_{4}\right)$ dan kalium permanganat (KMnO4), masing-maing sebanyak $5 \mathrm{ml}$ dan $10 \mathrm{ml}$., Memanaskan larutan sampai mendidih, 
Menamabahkan asam oksalat $\left(\mathrm{H}_{2} \mathrm{C}_{2} \mathrm{O}_{4}\right)$ sebanyak $10 \mathrm{ml}$. Menitrasi dengan menggunakan permanganat $\left(\mathrm{KMnO}_{4}\right)$ dalam keadaan masihpanas, hingga larutan berubah warna merah muda. Mencatat volume titra yang digunakan.

\section{Prosedur Kerja Titrasi BOD}

Penentuan nilai BOD didapatkan dari pengurangan nilai $\mathrm{DO}_{0}$ dan $\mathrm{DO}_{5}$, Memasukan sampel kedalam botol winkler, menutup sampai tidak ada gelembung udara, Menutup kembali kemudian menambahkan larutan mangan sufat $\left(\mathrm{MnSO}_{4}\right)$ dan larutan alkali iodida azida, Menunggu sampel sampai membentuk endapan coklat, Mempipet endapan dalam botol erlenmeyer $250 \mathrm{ml}$ sebanyak $25 \mathrm{ml}$. Menambahkan asam sulfat $\left(\mathrm{H}_{2} \mathrm{SO}_{4}\right)$ pekat sampai endapan larut kembali, Mentitrasi larutan natrium tiosulfat $\left(\mathrm{Na}_{2} \mathrm{~S}_{2} \mathrm{O}_{3}\right) 0,025 \mathrm{~N}$ sampai larutan berwarna kuning muda, Menambahkan beberapa tetes indikator amilum $\left(\mathrm{C}_{6} \mathrm{H}_{10} \mathrm{O}_{6}\right)$ sehingga larutan menjadi biru, Mentitrasi kembali larutan sampai menjadi bening dan mencatat volume titra yang digunakan.

\section{Pembuatan Alat Miniatur}

Membuat tempat pembakaran briket, membuat tabung penyimpan air, membuat lubang keci di atas tabung untuk dilalui uap air menuju turbin. Membuat penyangga tabung air dan ruang turbin uap. Kemudian Memasang turbin dan dinamo di atas tabung yang berisi air, menghubungkan tabung yang berisi air dan ruang turbin uap, mengunakan pipa besi. Air yang telah mendidih akan mengalami proses penguapan, proses penguapan inilah yang akan memutar turbin dengan kecepata rpm, di samping turbin terdapat dinamo yang akan meruba energi gerak menjadi energi listrik, energi listrik mengalir melalui kabel menuju penampungan energi yaitu aki. Setelah itu aki yang telah menampung energi langsung dilakukan pengukuran menggunakan multimeter, untuk mengukur arus dan tegangan. Pengujian ini bertujuan untuk mengetahui apakah alat yang telah dibuat berfungsi dengan yang diharapkan. Tahap selanjutnya adalah perhitungan daya atau watt yang di hasilkan dari miniatur pembangkit listrik tenaga uap dari hasil pembakaran briket.

\section{Prosedur Kerja Alat}

Menyiapkan tiga jenis zat cair, air sumur, air sungai, dan aquades. Kemudian mengukur BOD, COD, $\mathrm{PH}$ dan kekeruan air, masing-masing zat cair. Selanjutnya memasukan air sumur kedalam tabung miniatur. Menyalakan api ditungku pembakaran tunggu sampai air mendidih. Menunggu air sumur sampai mendidih Setelah air mencapai titik didih tekanan uap yang dihasilkan akan memutar turbin, dinamo yang akan mengkonfersi energi gerak menjadi energi listrik. Menambahkan LED mera, dan LED putih pada kabel penghubung dinamo Mengukur arus dan tegangan mengunakan multimeter digital. Mencatat hasil pengukuran arus dan tegangan. Mengulangi poin 3-8 dengan zat cair yang berbeda. 


\section{HASIL DAN PEMBAHASAN}

Tabel 1. Hasil pengukuran jenis fluida

\begin{tabular}{|l|l|c|c|c|c|}
\hline No & JenisFluida & $\begin{array}{c}\text { Kekeruhan } \\
\text { (NTU) }\end{array}$ & $\begin{array}{c}\text { Keasaman } \\
\mathbf{( P H )}\end{array}$ & $\begin{array}{c}\text { COD } \\
(\mathbf{m g} / \mathbf{L})\end{array}$ & $\begin{array}{c}\text { BOD } \\
(\mathbf{p p m})\end{array}$ \\
\hline 1 & Aquades & 0,0 & 5,6 & 63,2 & 2,2 \\
\hline 2 & Air sumur & 1,2 & 5,5 & 110,6 & 1,1 \\
\hline 3 & Air sungai & 6,5 & 5,2 & 189,6 & 0,2 \\
\hline
\end{tabular}

Tabel 2. Pengaruh jenis fluida terhadap daya yang dihasilkan

\begin{tabular}{|c|c|c|l|}
\hline Jenis Fluida & DAYA (Watt) & $\mathbf{I}(\mathbf{A})$ & $\mathbf{V}($ Volt) \\
\hline AQUADEST & 0,021 & 0,0118 & 1,749 \\
\hline SUMUR & 0,006 & 0,00344 & 1,645 \\
\hline SUNGAI & 0,004 & 0,00238 & 1,717 \\
\hline
\end{tabular}

Pada penelitian ini digunakan tiga jenis sampel fluida nilai arus dan tegangan yang diperoleh masing-masing dengan nilai rata-rata tegangan diantaranya: aquades $0,0118 \mathrm{~A}$ dan 1,749 Volt, air sumur $0,00344 \mathrm{~A}$ dan 1,645 Volt, dengan air sungai $0,00238 \mathrm{~A}$ dan 1,717 Volt, pada hasil pengukuran telah terbukti dapat menyalakan lampu LED merah 1,6 Volt.

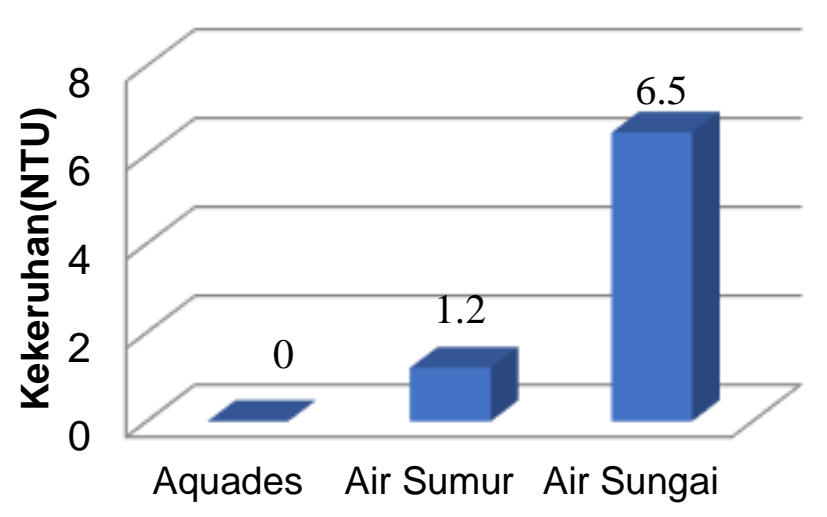

Gambar 1. Diagram kekeruhan berbagai jenis fluida 


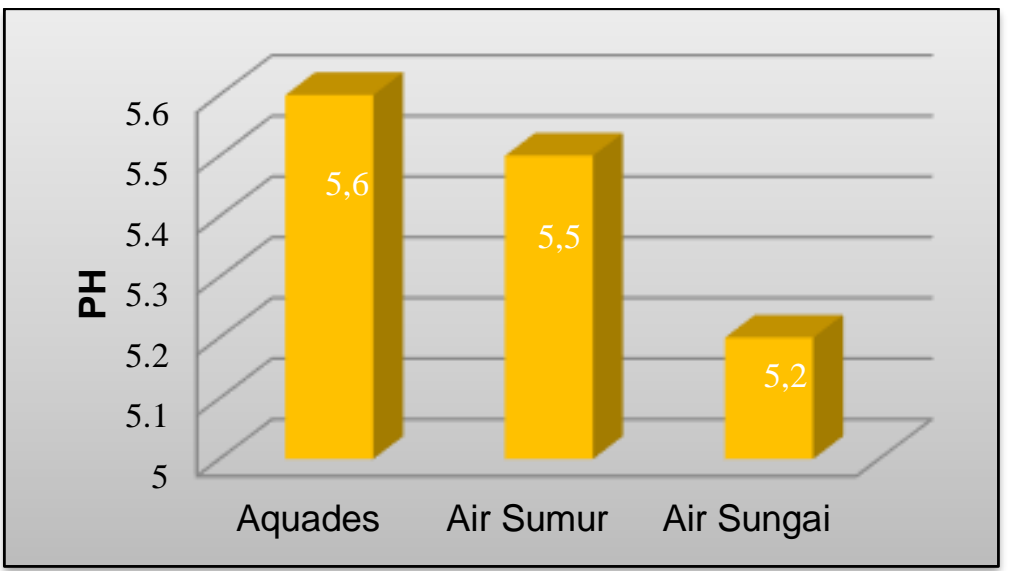

Gambar 2. Diagram PH berbagai jenis fluida

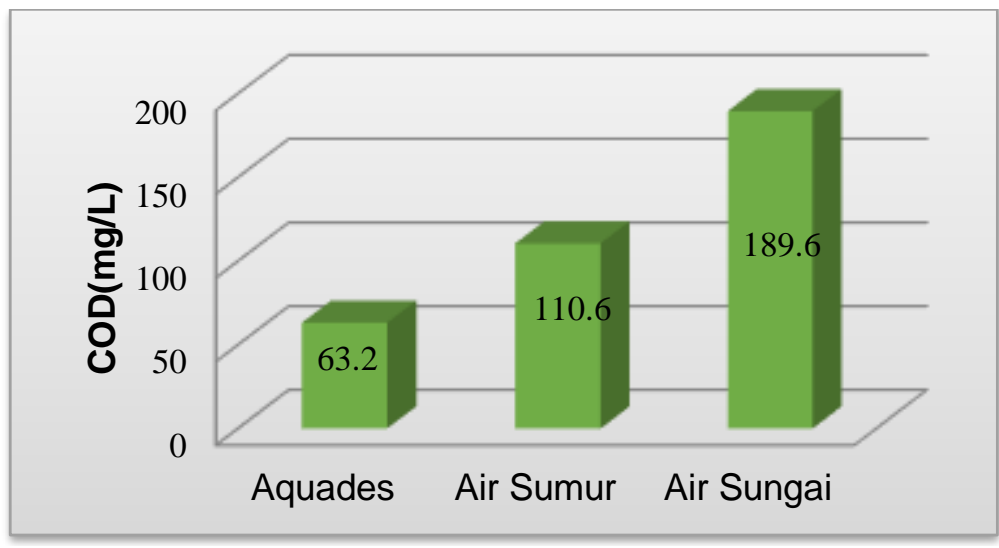

Gambar 3. Diagram kandungan COD berbagai jenis fluida

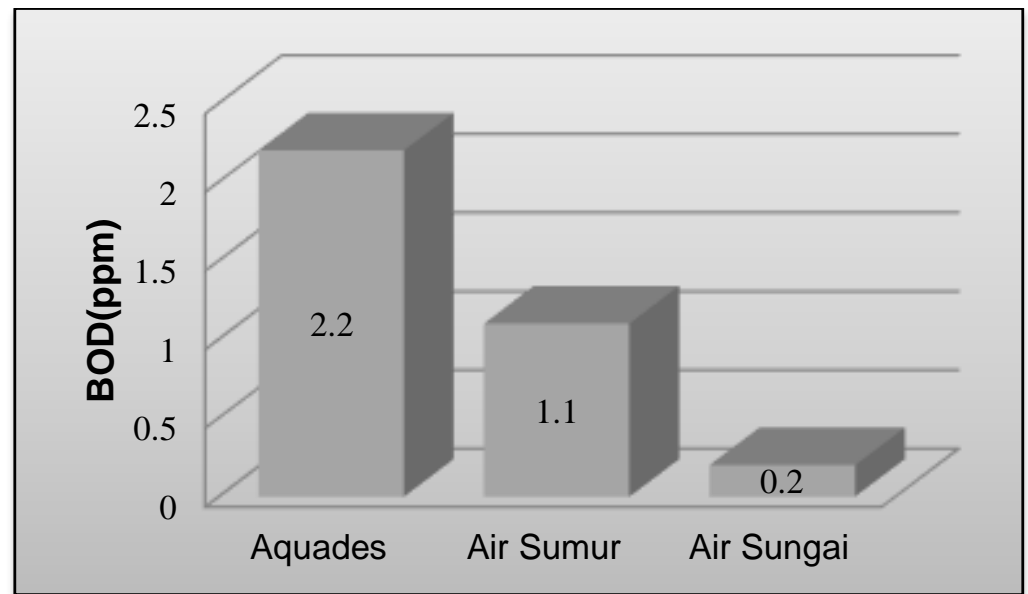

Gambar 4. Diagram kandungan BOD berbagai jenis fluida

Pengaruh tingkat kekeruhan air terhadap daya yang dihasilkan. kekeruhan berbanding terbalik terhadap daya semakin besar tingkat kekeruhan 6,5 NTU pada air maka semakin lambat perputaran turbin karena tekanan uap yang dihasilkan sangat kecil saat mengalami titik didih sehingga semakin rendahdaya listrik yang dihasilkan 0,004Watt, sebaliknya jika tingkat kekeruhan air semakin kecil 0,0 NTU maka semakin cepat turbin berputar karena tekanan 
uap yang dihasilkan saat mengalami titik didih sangat besar sehingga daya listrik yang dihasilkan pula semakin tinggi 0,021 Watt.

Pengaruh tingkat keasamanterhadap daya yang dihasilkan. Keasaman berbanding lurus terhadap daya semakin tinggi tingkat keasaman 5,6 pH maka turbin dapat berputar cepat karena berpengaruh terhadap tekanan uap yang dihasilkan semakin besar saat air mengalami titik didih, sehingga semakin tinggi daya listrik yang dihasilkan 0,021Watt, sebaliknya jika tingkat keasaman semakin rendah 5,2 $\mathrm{pH}$, maka turbin yang berputar semakin lambat karena tekanan uap mempengaruhi perputaran turbin terhadap titik didih yang dihasilkan sehingga daya listrik yang dihasilkan semakin kecil 0,004 Watt.

Pengaruh COD pada air terhadap daya yang dihasilkan. Kandungan COD berbanding terbalik terhadap daya listrik yang dihasilkan Semakin tinggi kadar COD 189,6 mg/L dalam airmaka semakin lambat perputaran turbin karena kandungan COD pada air mempengaruhi titik didih air semakin besar nilai COD semakin lambat air mengalami titik didih, sehingga semakin rendah 0,004 Watt daya listrik yang dihasilkan. Sebaliknya semakin rendah kadar COD 63,2 mg/L dalam air maka semakin cepat perputaran turbin karena kandungan COD pada air mempengaruhi titik didih air semakin cepat sehingga daya listrik yang dihasilkan semakin besar 0,021 Watt.

Pengaruh kadar BOD terhadap daya listrik yang dihasilkan.Kandungan BOD pada air berbanding lurus terhadap daya listrik yang dihasilkan, semakin tinggi 2,2 ppm kadar BOD dalam air maka turbin akan berputar semakin kencang karena tekanan uap besar, kadar BOD pada air akan mempengaruhi titik didih air sehinggasemakin tinggi0,021 Watt daya listrik yang dihasilkan. Sebaliknya semakin kecil0,2 ppm kadar BOD dalam air maka turbin berputar lambat karenakadar BOD pada air akan mempengaruhi titik didih air sehingga kecildaya listrik yang dihasilkan 0,00408646 watt.

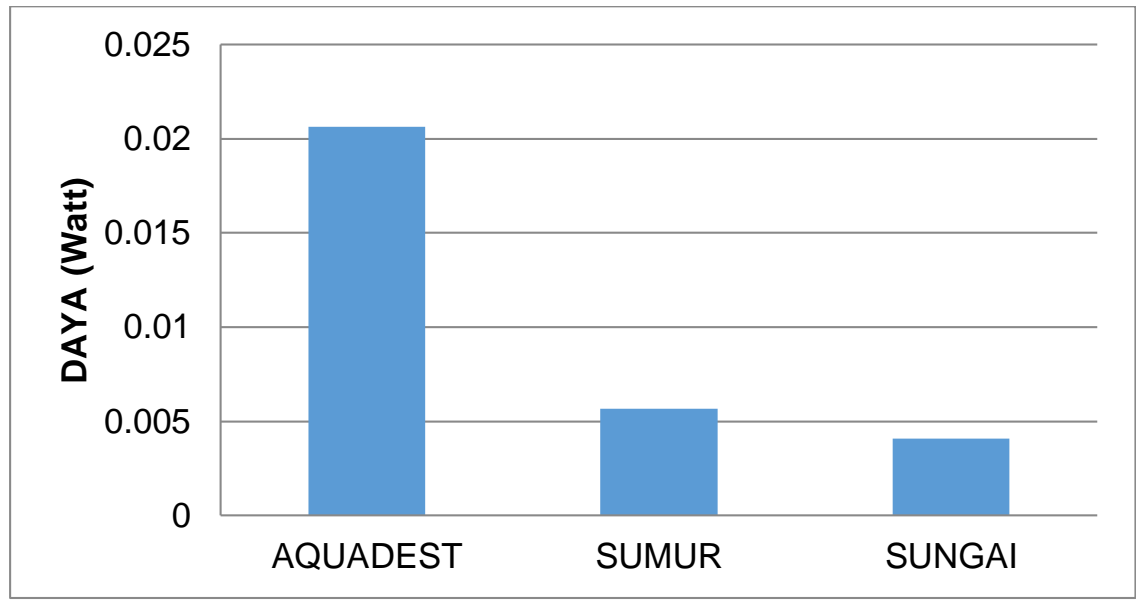

Gambar 5. Diagram pengaruh jenis fluidaterhadap daya listrik yang dihasilkan

Pada penelitian ini mengunakan tiga jenis sampel fluida yaitu aquadest, air sumur dan air sungai. Variabel tetap volume air $2000 \mathrm{ml}$ dan briket tempurung kelapa dengan massa 1048 gram. Daya yang dihasilkan pada aquades adalah 0,021 watt, daya yang dihasilkan pada air sumur 0,006 watt, daya yang dihasilkan pada air sungai 0,004 watt. 
Pada grafik diatas menyatakan jenis fluida berpengaruh terhadap daya listrik yang dihasilkan. Semakin rendah tingkat kekeruhan pada air 0,0 NTU, maka $\mathrm{pH}$ air akan mendekati netral $5,6 \mathrm{pH}$, kadar COD dalam air semakin rendah $63,2 \mathrm{mg} / \mathrm{L}$, dan kadar BOD pada air semakin tinggi2,2 ppm maka daya listrik yang dihasilkan semakin tinggi 0,021 karena daya listrik berbanding terbalik terhadap kekerhuan air, berbanding lurus terhadap $\mathrm{pH}$ air dan berbanding terbalik terhadap kandungan COD dalam air serta berbanding lurus terhadap kandungan BOD pada air.

Sebaliknya jika semakin tinggi tingkat kekeruhan air 6,5 NTU, maka pH air akan mendekati asam 5,2 pH, kadar COD dalam air semakin tinggi 189,6 mg/L, dan kadar BOD pada air semakin rendah 0,2 ppm maka daya listrik yang dihasilkan lebih kecil 0,004 Watt.Dapat disimpulkanpada penelitian ini dari ketiga sampel penelitian masing-masing yaitu aquades, air sumur, dan air sungai. Berdasarkan penelitian yang telah dilakukan dapat disimpulkan bahwa jenis fluida mempengaruhi besar daya yang dihasilkan.

\section{SIMPULAN}

Berdasarkan penelitian yang telah dilakukan dapat disimpulkan bahwa jenis fluida yang dibedakan atas parameter kekeruhan, COD, BOD, dan $\mathrm{pH}$ mempengaruhi daya listrik yang dihasilkan. Daya listrik tertinggi dihasilkan oleh miniatur dengan jenis fluida aquades yaitu sebesar 0,021 watt. Sedangkan sampel air sumur dan air sungai diperoleh daya listrik masing-masing sebesar 0,006 watt dan 0,004 watt.

\section{DAFTAR PUSTAKA}

Ali, Azwar, 2013 Kajian Kualitas Air Dan Status Mutu Air Sungai Metro Di Kecamatan sukun kota Malang : Jurnal Bumi Lestari Vol.13. No.2

Anita, Agnes, 2005 Perbedaan Kadar BOD, COD, TSS, dan MPN Coliform pada Air Limbah Sebelum dan Sesudah Pengolahan di RSUD Nganjuk. Jurnal Kesehatan Lingkungan. Vol.1.No.2

Fardiaz, Srikandi, 1992 Polusi Air Dan Udara. Yoggyakarta : Kanisius

Hermansyah 2017 Rancang Bangun Insinerator dua tahap solusi mengatasi populasi udara pada pembakaran. Makassar : uin press

Marsudi, Djiteng. 2011 Pembangkit EnergiLlistrik, edisi kedua. Jakarta : Erlangga. 